\title{
Evaluation of Microbial Contamination using various Air Sampling Techniques in Operation Theatres
}

\author{
K. Vijitha Alva and Thomas S. Kuruvilla* \\ Department of Microbiology, Father Muller Medical College, Mangalore, Karnataka- \\ 575002, India \\ *Corresponding author
}

\section{A B S T R A C T}

Keywords

Air sampler, Operation theaters, Air contamination, mean microbial count

Article Info

Accepted:

15 December 2019 Available Online:

20 January 2020
Microbial contamination of the Operation theatres (OT's) continues to increase the prevalence of nosocomial infections. Our study evaluates the microbial contamination using various air sampling techniques in OT's and find a suitable technique to assess air quality. A total 151 air samples were collected from various OT's of our tertiary care centre.76 samples were collected by an active method using an air slit sampler and 75 samples were collected by passive settle plate method using 5\% Sheep blood agar in $9 \mathrm{~cm}$ petri-plates. The mean microbial count of the both active and passive sampling method in OT's was 16.439 colony forming units $(\mathrm{CFU}) / \mathrm{m}^{3}$ and $13.480 \mathrm{CFU} / \mathrm{m}^{3}$ respectively. In most OT's CFU $/ \mathrm{m}^{3}$ were in normal limits. The labor OT at rest, exceeded the maximum limit value of active method $<35 \mathrm{CFU} / \mathrm{m}^{3}$ and of the passive method $<5 \mathrm{CFU} / 9 \mathrm{~cm} / \mathrm{h}$. The Oncology OT also exceeded the maximum limit value of the active method $<180 \mathrm{CFU} / \mathrm{m}^{3}$ and passive method $<25 \mathrm{CFU} / 9 \mathrm{~cm} / \mathrm{h}$. The most common isolate in both methods was Coagulase negative Staphylococcus (CoNS). The present study demonstrates that the active sampling method is better than the passive method to judge the microbial air quality in our tertiary care centre and the most common isolate was CoNS.

\section{Introduction}

The OT complex is the heart of any major surgical hospital. A good operating theatre design meets the functional needs of a theatre and must pay careful consideration to traffic patterns, the number and configuration of nearby operating rooms, the space required for staff, administration and storage, provisions for sterile processing and systems to control air borne contaminants (Sammy A.Benna et al., 2012). Modern operating theatres have a conventional plenum ventilation with filtered air where particles of $5 \mathrm{~mm}$ in size are removed. Few countries have set bacterial threshold limits for conventionally ventilated operating rooms, although most recommend 20 air changes per hour to obtain $50 \pm 150$ 
colony forming units $/ \mathrm{m}^{3}$ of air. There are no standardized methods for bacterial air sampling or its frequency.

In today's operating environment, more than half of clean surgical-site infection pathogens originate from normal skin flora of patients or staff. 1-3 bacteria on skin squames, lint and other dust get into the air in the operating theatre and by turbulent air currents that deposit on surfaces. To reduce prolonged morbidity and healthcare costs associated with these infections, airborne bacteria and other sources of contamination must be reduced to a minimum by the choice of staff theatre dress, patient preparation and draping, education of personnel and design and controlled ventilation by using High Efficiency Particulate Air (HEPA) in operating theatres (S Dharan et al., 2002). The dose of contaminating micro-organisms required to produce infection is very low when foreign material is present at the site. As few as 10 CFU are estimated to be the safe bacterial content per cubic meter of air in an operating theatre where prosthetic replacement arthroplasties are performed (MLV French et al., 1980; L Arrowsmith et al., 1985; C.Napoli et al., 2012).

Many developing countries have reported high post operative infection rate in their hospitals, ie., $15 \%$ from Brazil 11\% from Mumbai, $21.66 \%$ from Karnataka, 5\% in USA and Europe despite having a well maintained condition and controlled ventilation system (CCVS) (MA Melhado et al., 2006). A study by Rumpa Saha et.al found the presence of Methicillin sensitive Staphylococcus aureus (MSSA), Methicillin resistant Staphylococcus aureus (MRSA), Pseudomonas aeruginosa and fungi in theatre environment (Rumpa Saha et al., 2017).

K Singh suggested first cleaning by using surface disinfectants and periodic fumigation of the OT's as a preventive measure (K Singh et al., 2013). J Jawaed on the contrary found total bacteriological count in air was high but surfaces showed less bacterial counts (J Jawaed et al., 2008). C Pasquarella et.al also assessed microbial air contamination by active and passive sampling methods and concluded beyond doubt that microbiological monitoring is a useful tool for assessment of the contamination of operating theatres in order to improve air quality (C Pasquarella et al., 2012).

\section{Materials and Methods}

Air sampling can be done by many methods ranging from simple to complex (ISO 14644-1 1999; The United stated Pharmacopeia Chapter 2011). The present prospective analytical study was conducted from January to December 2018 after ethical clearance in various OT's of a tertiary care hospital. The culture plates were incubated and analyzed in the department of Microbiology. The sample size (Sammy A.Benna et al., 2012) was 151 calculated by sample size formula... $\mathrm{N}=\mathrm{Z}^{2}$ (1$\alpha / 2) \times p(1-p) / \alpha^{2}$ Where, $Z=1.96$, estimated proportional $(p)=0.11$, estimation error $(\alpha)=$ 0.05. All air samples collected from the operation theatres by both active and passive methods were included in the study. Air samples from all ICU's, post operative wards and other wards were not included.

(ISO 14644-1 1999; The United stated Pharmacopeia Chapter 2011; EU GMP Guideline:1997; W.Whyte, et al., 2007; A. A Anderson et al., 1958).

\section{Active method}

A single sample was collected from each OT by both methods simultaneously. The air sampler "Single stage slit type air sampler" called Hi Air Flow LA 474, from Hi media Laboratories Pvt Ltd, India was checked for 
cleanness before use by following the manufacturer's instructions. The theatre to be sampled was left vacant and doors shut for a minimum of 15 minutes, to 1 hour. A sterile $5 \%$ sheep blood agar plate was placed after pre- sterility testing by overnight incubation at $37^{\circ} \mathrm{C}$, into the air sampler under aseptic precautions. The air sampler equipment was placed in the middle of the theatre table at the height of 2-5 feet and secured on a trolley. It was then switched on manually before leaving the room. The sampling equipment determines the volume of air sample. Sampling volume needs to be more than $250 \mathrm{~L}$ and optimally around 1600 L. Once sampling was completed, the agar plate was removed aseptically, labeled and send to the microbiology laboratory for incubation and subsequent processing.

\section{Passive method}

Simultaneously settle plates which are standard petri-dishes of $9 \mathrm{~cm}$ diameter containing culture media were placed on tables or a stool about a meters height and a meter from the side walls and left open for 10 minutes, each plate covering all the 4 corners and centre both at rest and during activity. After exposure, the plates are covered with their lids. Then sent to the microbiology laboratory and incubated at $37^{\circ} \mathrm{C}$ for $18-24$ hours. After incubation, the total number of CFU was noted manually and results were expressed in CFU (Colony Forming Units) / Plate / time or in CFU / meter square / hour ( $\mathrm{T}$ Tshokey et al., 2016).

The above two methods were done in the OT both at rest and also during movement of OT personnel like operating surgeons, assistants and nurses. In order to get the CFU values in $\mathrm{CFU} / \mathrm{m}^{3}$ for comparison with the commercial sampler, first the settling rate was calculated. For a $90 \mathrm{~mm}$ plate (surface area $\approx 63.6 \mathrm{~cm}^{2}$ ) exposed for 10 minutes, the settling rate was calculated and expressed as CFU/ $/ \mathrm{m}^{2} / \mathrm{min}$ ( $\mathrm{T}$ Tshokey et al., 2016).

To correlate the CFU's present on the agar plate to the most probable number (MPN) of microorganism $/ \mathrm{m}^{3}$ of air sampled using the Air Sampler the following formula was used as per manufacturers instructions (LA474 Air slit sampler, Hi-media Kit insert)

$\operatorname{Pr}=\mathrm{N}[1 / \mathrm{N}+1 /(\mathrm{N}-1)+1(\mathrm{~N}-2)+\ldots \ldots . .+$ $1 /(\mathrm{N}-\mathrm{r}+1)]$

Where, $\operatorname{Pr}$ - Most probable number of microorganisms in the volume of air sampled $\mathrm{N}$ - Number of holes on microflow sampling head

$\mathrm{R}$ - Number of CFUs on the agar plates after incubation.

\section{In active method}

The sampled volume number: $1600 \mathrm{~L}\left[1.6 \mathrm{~m}^{3}\right]$

Number of colonies formed are:126

The calculated corrected number of colonies [ using feller table]: 152

Most probable number of colonies in air sample $=\operatorname{Pr} / \mathrm{N}$

$=152 / 1.6$

$=95 \mathrm{CFU} / \mathrm{m}^{3}$

\section{In passive method}

Number of colonies formed are : 30 $\mathrm{CFU} / \mathrm{m}^{2} / \mathrm{min}$.

The relation between $\mathrm{CFU} / \mathrm{m}^{2} / \mathrm{min}$ and $\mathrm{CFU} / \mathrm{m}^{3}$ will be analysed after getting the $\mathrm{CFU} / \mathrm{m}^{2} / \mathrm{min}$ from $\mathrm{CFU} / \mathrm{m}^{3}$ After getting the $\mathrm{CFU} / \mathrm{m}^{2} / \mathrm{min}$ from the number of colonies with 10 minutes exposure, the $\mathrm{CFU} / \mathrm{m}^{3}$ of air was calculated using the formula of Parker. 
Parker stated that 'the number of particles settling on $1 \mathrm{~m}^{2} / \mathrm{min}$ is equal to the number of such particles in $0.3 \mathrm{~m}^{3}$ of air. The conversion of $\mathrm{CFU} / \mathrm{m}^{2} / \mathrm{min}$ for the settle plate into $\mathrm{CFU} / \mathrm{m}^{3}$ using this formula makes it directly comparable to the commercial sampler values in $\mathrm{CFU} / \mathrm{m}^{3}$.

$$
1 \mathrm{~m}^{2} / \mathrm{min}=0.3 \mathrm{~m}^{3} \text { of air }
$$

Most probable number of colonies in air sample $=30 \times 0.3$

$=9 \mathrm{CFU} / \mathrm{m}^{3}$

Identification of the different types of the colonies in the OT air sampling plate

(Mackie and Mc Cartney Practical Medical Microbiology. 2008)

The smears from the colonies (Bacterial / Fungal) that grew on the culture plate were identified by standard microbiological techniques. Isolates that were Gram positive oval yeast like budding cells were speciated by the germ tube test and the use of Chrome agar and cleanliness class interpretations were done as depicted in Table: 1 .

\section{Results and Discussion}

A total of 151 air samples was collected from the Main OT Complex, Cardiac OT, Oncology, Opthalmology \& Labor OT of the hospital.76 samples were collected by active method of which 48 samples were taken at rest and 28 samples were taken during activity. 75 samples are collected by passive method of which 60 samples were taken at rest and 15 samples were taken during activity. In active method 50\% samples showed growth and 50\% showed no growth. In the passive method $33.3 \%$ samples showed growth and $66.7 \%$ no growth was seen as shown in Table 2 \& Fig: 1 .

There was a statically significant correlation between the results obtained by the active and passive air sampling methods based on the organism present and absent. The mean value of at rest and in activity by both methods and organisms isolated are depicted in Table 3,4 \& 5

The mean microbial count of the both active and passive sampling method in OT's was $16.439 \mathrm{CFU} / \mathrm{m}^{3}$ and $13.480 \mathrm{CFU} / \mathrm{m}^{3}$ respectively. In most of our OT's the CFU $/ \mathrm{m}^{3}$ were within normal limits. The labor OT at rest, exceeded the maximum limit value of active method $\left[<35 \mathrm{CFU} / \mathrm{m}^{3}\right]$ and of the passive method $[<5 \mathrm{CFU} / 9 \mathrm{~cm} / \mathrm{h}]$. The Oncology OT also exceeded the maximum limit value of the active method $\left[<180 \mathrm{CFU} / \mathrm{m}^{3}\right]$ and passive method $[<25$ $\mathrm{CFU} / 9 \mathrm{~cm} / \mathrm{h}]$. Both the above reference values are suggested by the UK Health Department Memorandum (S Dharan et al., 2002).

The most common isolate in both the air sampling methods was Coagulase negative Staphylococcus (CoNS) and all the Gram positive and Gram negative isolates were considered potential pathogens for surgical site infections. On the whole the significance was higher when the sampling was done by the commercial air sampler than by the settle plate method.

The currently available methods in air sampling are sedimentation (settle plate), impactors (slit samplers, sieve samplers, centrifugal samplers and impingement samplers) and gelatin membrane filtration (MLV French et al., 1980; L Arrowsmith et al., 1985).

Settle plates allow biological particles to "sediment" on it, but Impactors on the other hand draws air into the sampler which then directs the air stream at the collection agar. ${ }^{4}$ The most innovative air sampling technology is the gelatin membrane filtration method 
where air is sampled at a programmable flow rate and passes through a gelatin membrane filter, which captures the microbes. This is the only sampling method with an absolute retention rate and the only method that also reliably captures airborne viruses (L Arrowsmith et al., 1985).

When selecting an air sampling method, it is important to consider the benefits and problems connected with each method and to determine which sampler is best suited for specific needs and requirements (L Arrowsmith et al., 1985).

Data indicates that prevention of postoperative infection is dependent on several factors including effective theatre design, sterilisation and disinfection procedures, good surgical techniques, bacterial contamination of theatre air, discipline which includes restricting the movement in OT's (C.Napoli et al., 2012).

Currently, the lack of set guidelines for air sampling makes evaluation of results from different studies complicated. Regular monitoring of the OT environment having an adequate controlled ventilation system of HEPA filters will go a long way in ensuring clean air in the OT (I.Oren et al., 2001) The same is true even for fungal air contamination (WJ Sayer et al., 1972)

The European Union's Guidelines to good manufacturing practice, classify the different environments based on airborne practice and microbial contamination measured by active and passive sampling. It can be seen that many empty theatres fall in to Class B [ $10 \mathrm{CFU} / \mathrm{m}^{3}$, $5 \mathrm{CFU} / 9 \mathrm{~cm} / 4 \mathrm{hr}=1.25 \mathrm{CFU} / \mathrm{h}$ ], More than half of the OT's showed class $\mathrm{C}$ bacterial contamination $\left[100 \mathrm{CFU} / \mathrm{m}^{3}, 50 \mathrm{CFU} / 9 \mathrm{~cm} / 4\right.$ $\mathrm{hr}=12 \mathrm{CFU} / \mathrm{h}$ ] (C Pasquarella et al., 2012). In the present study majority of our OT's showed Class B bacterial contamination by both methods except the Oncology OT and
Labor OT which showed class C bacterial contamination in active method and Class $\mathrm{D}$ [100CFU/ CFU $/ 9 \mathrm{~cm} / 4 \mathrm{hr}=25 \mathrm{CFU} / \mathrm{h}$ ] bacterial contamination in passive method. There is a statically significant correlation between the results obtained by the two sampling methods. Such correlation was not always apparent, showing the several other factors can affect their relationships such as particle size or ventilation parameters. It should also be considered that active sampling methods often work in a very narrow spatial and temporal range compared with the longer exposure times of settle plates.

Our present study revealed the presence of a number of organism. Coagulase negative Staphylococcus (CoNS) being more prevalent than Methicillin resistant Staphylococcus (MRCoNS) at rest. Klebsiella pneumoniae \& Acinetobacter baumannii were the only two Gram negative organisms and fungi by sampling at rest of the Main OT complex. A study by Napoli from Italy documented that both techniques can be used for the bioburden surveillance but passive sampling is best for quantitative evaluation of hospital airborne bacteria (C.Napoli et al., 2012).

Our study found that settle plates were less sensitive for the collection of fungi than active samplers. The sensitivity of the settle plate could be improved by increasing the exposure time, as suggested by the European Union guidelines to Good manufacturing Practice where threshold values are given for $9 \mathrm{~cm}$ diameter settle exposed for 4 hours (C Pasquarella et al., 2012).

T. Shokey's study also showed that the differences in contaminations were highly significant when the sampling was done by the commercial sampler in empty or in-use operation theatre. The settle plate method had some outlier readings and occasionally gave inconsistent results. 
Table.1 Interpretation- Clean Room Classification according to cleanliness class (JIS B 99201998) ( ISO 14644-1 1999)

\begin{tabular}{|c|c|c|}
\hline Class $5 \& 6$ & $\begin{array}{c}\text { Special operating room(Transplant theatres, Cardio } \\
\text { thoracic theatres),Special treatment room (burns and } \\
\text { leukemia treatment rooms) }\end{array}$ & 0-10 CFU $/ \mathrm{m}^{3}$ \\
\hline Class 6 \& 7 & Recovery room (ICU,CCU,NICU) & $10-100 \mathrm{CFU} / \mathrm{m}^{3}$ \\
\hline Class $7 \& 8$ & $\begin{array}{c}\text { Regular operating rooms, all laboratories, Pharmaceutical } \\
\text { rooms, rooms for infectious diseases }\end{array}$ & 100- $200 \mathrm{CFU} / \mathrm{m}^{3}$ \\
\hline
\end{tabular}

Table. 2 Comparative results of active and passive air sampling in OT's

\begin{tabular}{|c|c|c|c|c||}
\hline & & \multicolumn{2}{|c|}{ Method } & \multicolumn{2}{|c|}{} \\
\hline \multirow{2}{*}{ Organism } & & Active & Passive & \multicolumn{2}{c|}{ Total } \\
\hline & & 38 & 50 & 88 \\
\hline & Present & $50.0 \%$ & $66.7 \%$ & $58.3 \%$ \\
\hline & 38 & 25 & 63 \\
\hline & Total & $50.0 \%$ & $33.3 \%$ & $41.7 \%$ \\
\hline & 76 & 75 & 151 \\
\hline & $100.0 \%$ & $100.0 \%$ & $100.0 \%$ \\
\hline
\end{tabular}

Chi square test: $\mathrm{X}^{2}=4.312 \mathrm{p}=.038$, significant

Table.3 The mean value of both air sampling methods

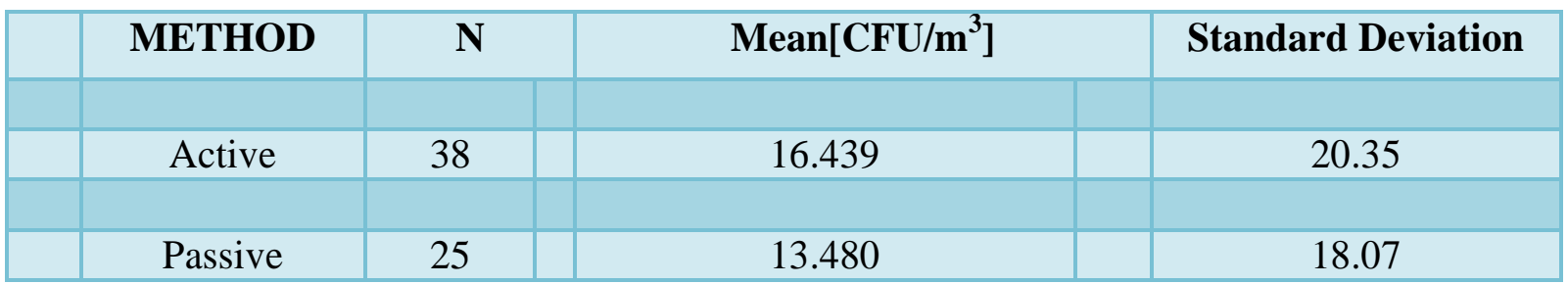

Table.4 The mean value at rest and in activity by both air sampling methods

\begin{tabular}{|c|c|c|c|}
\hline & & Method & Mean value \\
\hline & & & $\mathrm{CFU} / \mathrm{m}^{3}$ \\
\hline & rest & 1. Active method & 18.20 \\
\hline & & 2 Doccive method & 1000 \\
\hline I & activity & 1 Active method & 1632 \\
\hline $\mathbf{n}$ & & & \\
\hline & & 2. Passive method & 19.80 \\
\hline
\end{tabular}


Table.5 Organisms isolated by the active \& passive sampling method

\begin{tabular}{|c|c|c|c|c|}
\hline Identified organisms & $\begin{array}{c}\text { Active method } \\
\text { Sample size }\end{array}$ & $\%$ & \multicolumn{2}{|c|}{$\begin{array}{c}\text { Passive method } \\
\text { Sample size }\end{array}$} \\
\hline $\begin{array}{c}\text { Methicillin resistant } \\
\text { Coagulase negative } \\
\text { Staphylococcus }\end{array}$ & 4 & $5.3 \%$ & 5 & $6.7 \%$ \\
\hline $\begin{array}{c}\text { Coagulase negative } \\
\text { Staphylococcus }\end{array}$ & 23 & $30.3 \%$ & 15 & $20 \%$ \\
\hline Micrococcus & 6 & $7.9 \%$ & 1 & $1.3 \%$ \\
\hline Klebsiella pneumoniae & 1 & $1.3 \%$ & 2 & $2.7 \%$ \\
\hline Acinetobacter baumannii & 3 & $3.9 \%$ & 0 & $0 \%$ \\
\hline Candida albicans & 2 & $2.6 \%$ & 2 & $1.3 \%$ \\
\hline Candida krusei & 2 & $2.6 \%$ & 2 & $1.3 \%$ \\
\hline
\end{tabular}

Fig.1 Percentage of growth by both methods of air sampling

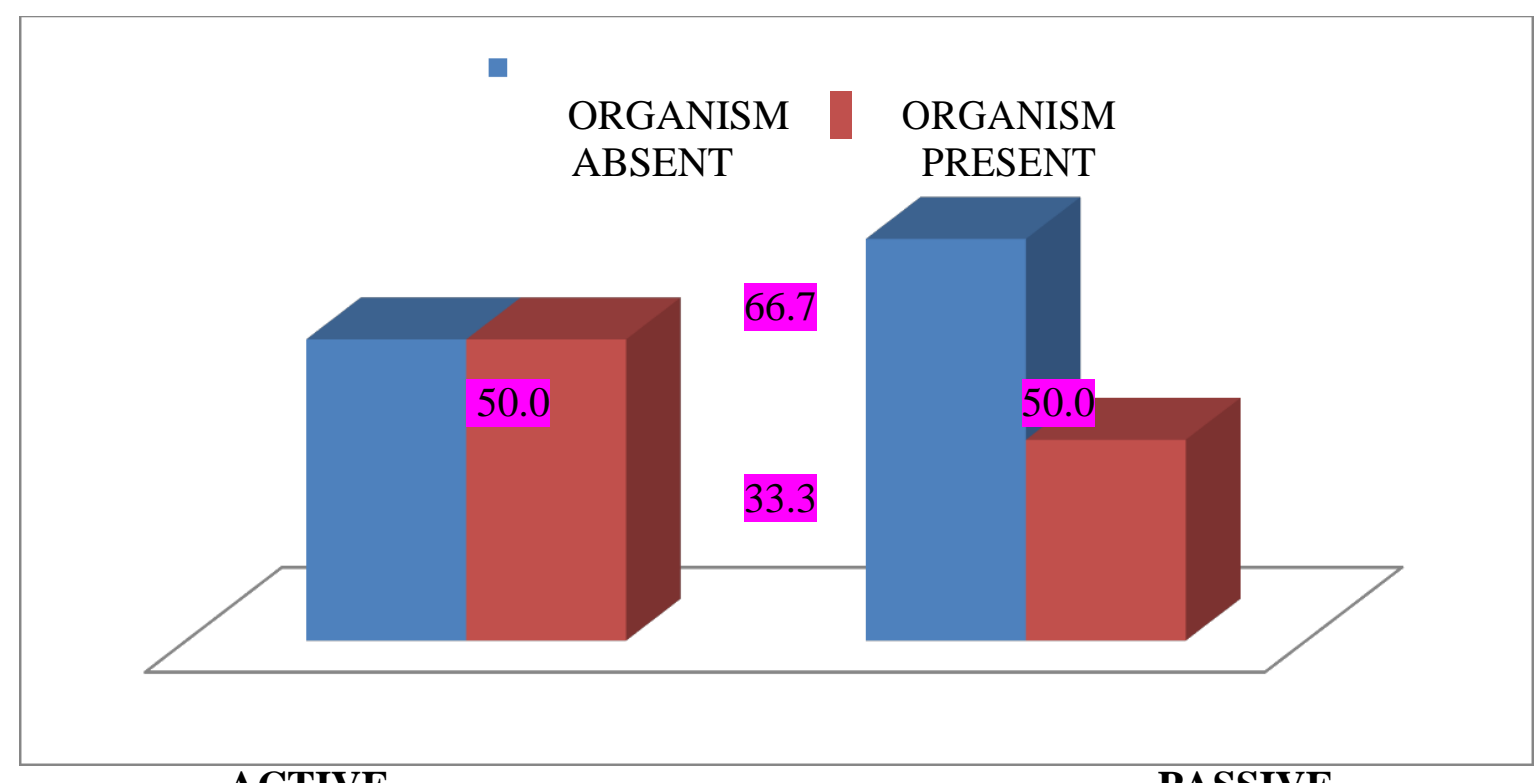

ACTIVE

PASSIVE

Thus, while using the settle plate method, it would be more reliable to repeat for few sessions with multiple agar plates and take a mean reading ( $\mathrm{T}$ Tshokey et al., 2016).

It is clear from our study that despite varying opinions about both active and passive methods of sampling by various researchers, the slit sampler is at an advantage being a more sensitive method than the settle plate method and thus is a useful tool for any healthcare facility.

\section{References}

A. A Anderson. 1958. New air sampler for the collection, sizing, and enumeration of viable air borne particles. Bacteriol. 76:471-484.

C.Napoli,V. Marcotrigiano, MT. Montagna. 
2012. Air sampling procedures to evaluate microbial contamination: A Comparison between active and passive methods in operating theratres. BMC Public health. 12:594-99.

C Pasquarella, P vitali, et.al. 2012. Microbial air monitoring in OT's: Experience at the university hospital of Parma. $\mathrm{J}$ of hosp inf. 81;50-57.

ISO 14644-1. 1999. Clean rooms and associated controlled environments, Part 1: Classification of air cleanliness. International Organization for Standardization Technical Committee.(ISO TC 209).

EU GMP Guideline.1997. Values for microbiological monitoring in the operational state, for the manufacture of sterile products.

I Oren, N Haddad, R Finkelstein,J M Rowe. 2001 Invasive pulmonary aspergillosis in neutropenic patients during hospital construction: Before and after chemoprophylaxis and institution of HEPA filters. Am J Hematol. 66:257-62.

J Jawed,R Hafeez, M Zubair,MS Anwar,M Tayyib, S Husain. 2008. Bacterial contamination of air surface and equipment in OT's of tertiary care hospital in Lahore. Biomedica. 24:99102.

K Singh, F A Dar, K Kishore. 2013. Bacterial contamination in operating theatres of District Hospital Budgam of Kashmir Division. Inn $\mathbf{J}$ of Med and Health Sci. 3:62- 63 .

L Arrowsmith. 1985. Air sampling in operating theatres. J of Hosp Inf. 6:352353.

LA474 Air slit sampler, Hi-media Kit insert.

Mackie and Mc Cartney. 2008. Practical Medical Microbiology $14^{\text {th }}$ edition, edited by J.E.Collea, A.G.Fraser, B.P.Marmion, A.Simmons;

MA Melhado,JL. Hensen,M. Loomans. 2006. Review of ventilation systems in operating rooms in view of infection control. Proceedings of the 6th Int. Postgraduate Research Conf. in the Built and Human Environment, 6 - 7 April, Technische Universiteit Delft, $\mathrm{BuHu}$, University of Salford. 478-487.

MLV French, HE Eitzen, MA Ritter, DS Leland. 1980. Environmental control of microbial contamination in the operating room. Wound Healing and Wound Infection. Edited by: Hunt TK, Appleton-Century Crofis, New York. 254-261.

Rumpa Saha, Shreya Agarwal, Amir Maroof Khan. 2017. Air sampling procedures to evaluate microbial contamination: A comparison between active and passive methods at high-risk areas in a tertiary care hospital of Delhi. J of patient safety and Inf control. 5(1):18-23.

Sammy A.Benna. 2012. Infection control in OT. $\mathbf{J}$ of perioperative practice. 22(10):318- 323.

S Dharan and D Pittet. Infection Control Programme. J of Hosp Inf 2002. 51:7984.

The United stated Pharmacopeia Chapter[1116] 34 NF-29 2011,United States Pharmacopeail

Convention, INC. Rockwille, MD 20852.

Tshokey, P Somaratne, S Agampodi. 2016. Comparison of two air sampling methods to monitor operating room air quality and assessment of air quality in two operating rooms with different ventilation systems in the national hospital of Sri Lanka. Int J Inf Controll. 12:1- 8 .

W.Whyte, et.al. 2007. Collection efficiency and design of microbiological air samplers: Aerosol Science. 38:101-114.

WJ Sayer, NM Mac Knight, HW Wilson.1972. Hospital airborne bacteria as estimated by the Andersen sampler versus the gravity settling culture plate. Am J Clin Pathol. 58:558-566. 


\section{How to cite this article:}

Vijitha Alva, K. and Thomas S. Kuruvilla. 2020. Evaluation of Microbial Contamination using various Air Sampling Techniques in Operation Theatres. Int.J.Curr.Microbiol.App.Sci. 9(01):

37-45. doi: https://doi.org/10.20546/ijcmas.2020.901.005 